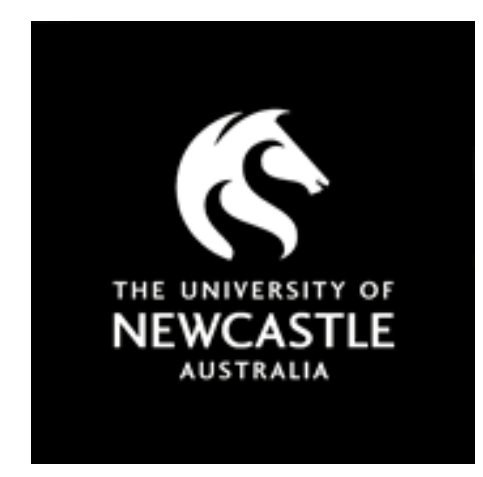

NOVA

University of Newcastle Research Online

nova.newcastle.edu.au

Stewart, Georgina; Forster, Daniella J. "Conclusion to special issue: academic publishing, philosophy of education and the future", Published in Educational Philosophy and Theory Vol. 49, Issue 2, p. 192-201. (2017)

Available from: $\underline{\text { http://dx.doi.org/10.1080/00131857.2015.1069034 }}$

This is an Accepted Manuscript of an article published by Taylor \& Francis Group in Educational Philosophy and Theory on 09/10/2017, available online:

http://www.tandfonline.com/doi/full/10.1080/00131857.2015.1069034.

Accessed from: http://hdl.handle.net/1959.13/1352691 


\title{
Academic publishing, philosophy of education and the future
}

\author{
Conclusion to Special Journal Issue \\ Georgina Stewart and Daniella Forster
}

This Special Issue has presented a series of conversational interviews with editors of leading journals in the field of philosophy of education. This concluding article synthesises the interviews and reflects on what this project offers to early career researchers including the interviewer-authors in this issue. The contributing writers are interested in their own prospects, as well as those of the field of philosophy of education, and indeed education, and society more generally, in the context of the turbulent changes currently remodelling academic lives and institutions. This has been an inspiring project to work on, producing these six interviews, on which this conclusion and special issue is based:

- Shaping the agenda of the global civil society: an interview with Michael Peters, by Richard Heraud and Marek Tesar.

- Publishing and intergenerational learning in philosophy of education: an interview with Paul Smeyers, by Daniella Forster.

- Insights from an editor's journey: an interview with Gert Biesta, by Christoph Teschers.

- [To be confirmed]: an interview with Bob Davis, by Kirsten Locke.

- Emerging perspectives on editorial ethics: an interview with Chris Higgins, by Liz Jackson.

- The long arc of knowledge: an interview with Nicholas Burbules, by Georgina Stewart.

Most of the Editors commented on the large amount of work involved in editing a journal: a demanding, time-consuming, but very rewarding and satisfying job. Paul Smeyers spoke of taking on the role after being approached by the publisher, when he realised there were few alternative candidates. Gert Biesta spoke of being curious to find out about the process of publishing from the inside, as well as regarding it as an honour to be asked, and being motivated by a wish to help the field. Michael Peters said his editing philosophy includes helping academics to realise that editing and publishing are related to having control over one's own ideas: more political and philosophical than simply the technical tasks of proofreading and editing. All the Editors are motivated by a wish to improve the field, and ultimately society.

An editor clearly needs to read a great deal: some of the Editors spoke about reading everything submitted, and everything published in the journal; or of having read thousands of papers in their time 
as editor; and the daunting commitment of time involved - about half a day per paper, or more. Several Editors spoke about the impact of the job on their own research output: one view being that the sheer time involved in editing a journal is detrimental to being an active researcher. Conversely, reading the work of so many other scholars can provide an editor with more motivation to write, while having limited writing time available encourages more decisiveness, and less perfectionism.

Journals and editors need to understand their consumers: who reads what, how and when. In recent decades, reading practices have undergone a major change from paper-based to screen-based, and some of the Editors speculated that paper-based journals will soon disappear entirely. The change to reading digitally is the latest in a series of historical iterations of how the disciplines of reading interact with the mediating technologies, with each change integrating new forms while retaining what is best in their heritage. Reading, and hence also writing, played an important part in the 18thcentury European development of human rights and the concept of equality, through widespread readership of seminal texts (such as Rousseau's epistolary novel Julie published in 1761). The contemporary situation, in which everything can be freely read, re-defines the relationship of the reader to the author, whereby reading and writing constitute a form of creative labour on the self, involving self-transformation, self-recognition, and the kinds of links that are possible between people in a digital world.

\section{Digital transformation of publishing}

Some of the Editors noted that the move to digital publishing has been advantageous for small areas such as philosophy of education, because it has made the published research in the field more accessible, and hence more widely read. An online journal is effectively a global journal, in terms of its potential readership, in contrast to former print-only days when only a finite number of copies of each issue were produced. Concomitantly, digital publishing changes a journal's identity, which is no longer associated with a particular nation, region, or learned society, and calls into question usages such as country names in journal titles, or season names to identify issues in each volume.

The digitisation of publishing has also meant that data on journal reading behaviour that were previously unavailable can now be collected, resulting in the rise of metrics such as impact factors, which are now being used for evaluation and policy decisions. The Editors expressed concern about the effects of the 'fetishization' of metrics on the field of educational research, and on the career trajectories of emerging academics. While recognising that the leading journals inevitably publish high quality research and rank highly according to metrics, the Editors downplayed the worth of journal rankings and impact factors based on citation indexes: firstly, because they are exclusionary, 
acting as mechanisms to perpetuate knowledge hierarchies at all levels - between journals within each field; between different academic fields; between large and small countries regionally; and in allowing continued global dominance of Euro-American knowledge systems. Journal metrics are also exclusionary in the sense that they are privatised: run not by academics but by publishing companies, and unavailable for public scrutiny; yet with power over academics through their influence on what is being funded, researched and published. Michael Peters connects journal metrics with the larger concept of 'big data' utilised in global finance and quantitative science, and suggests that the academic community needs a critical understanding of the history of big data systems in order to formulate a useful, philosophical response.

Digital systems have led to a massive increase in the speed of publishing, about which some of the Editors expressed ambivalence, seeing, on the one hand, advantages for scholars of getting their work published quickly, but on the other hand, the potential for distortion of the entire system of academic publishing, if speed is valued at the expense of all other criteria. Journal metrics add to the distorted high value placed on speed, because citations are measured only for the first 24 months after publication. Thus the natural sciences as 'high-speed disciplines' exert undue influence on academic publishing overall. Such quick cycles of research and publishing are almost irrelevant in a field such as philosophy of education, which has a much longer arc of knowledge, where the point is to add to existing arguments rather than to replace old knowledge with new knowledge, and in which new insights are still to be found in ancient sources, such as Plato.

By comparison with science, conventions of scholarship and genres of academic writing are much less standardised in disciplines such as philosophy of education, which again makes it slower to learn to evaluate and write good quality work. But discussion of the structure and nature of publishing cannot be held in isolation from consideration of the systems of appointment, advancement and reward in universities that determine career trajectories, especially for early career researchers.

The number of institutions of higher education has increased greatly in recent decades, and so has the overall volume of academic publishing. More and more people who work in higher education are being required to publish, and in consequence there has been a steady increase in the number of submitted manuscripts. Relatedly, the Editors recognised that increased pressure to publish is exerted on academics by national systems of performance-based research assessment. This pressure is paradoxical in relation to the opinion expressed by some of the Editors that new scholars are often pushed to try to publish too early, which can in turn lead to the experience of rejections. Gert Biesta 
advises junior scholars to invest time in writing high quality papers, although he acknowledges that quantity of publications is also important in the current environment.

In terms of supporting young scholars to achieve publication, Nicholas Burbules set up a discussion group for graduate students under the auspices of his journal, to teach them about the publishing process, and help them to think as reviewers and editors. Bob Davis talked about workshops for emerging researchers that are run by societies of philosophy of education in the United Kingdom and United States, to provide assistance in achieving publication. Michael Peters expressed strong opposition to systems of research assessment as symptomatic of the neoliberal culture of performativity, because these systems sacrifice quality for quantity, and are crippling for academics. Peters sees one key task for a journal editor as being to provide spaces for emerging scholars to experiment with innovative, academic forms of writing.

Online digital publishing has also transformed the world of academic journals by facilitating openaccess publishing, which is now mandatory for all publicly-funded research in the United Kingdom, with other nation-states likely to follow. The Editors applaud the democratic potential of open-access publishing in making research available to any reader, but are uncertain about its impact on how publishers might pay for the costs of producing a journal. The Editors expressed strongly negative views about the author-pays model, which is one way to fund open-access publishing, since requiring authors to pay journals to publish their work greatly increases competition for research funding. In this way, author-pays acts as another way of regulating what is researched and published, further disadvantaging fields such as philosophy of education by comparison with 'hard' sciences. The author-pays model is also problematic for young scholars who wish to follow the $\mathrm{PhD}$-by-publication route. Most of the Editors thought that models of publishing and expectations of profit from academic journals are likely to keep changing. So far, journals of philosophy of education have remained nonopen-access, although subscription rates vary widely. Some journals in philosophy of education are owned by learned societies, which can use the profits generated by the journal to benefit the disciplinary community.

A concurrent development is the emergence of open-source publishing, in which work does not go through traditional channels of formal peer review and editing. Many new open-source author-pays journals are being set up in hopes of profit, capitalising on: the increased pressure authors face to get published; the emergence of author-pays; and the new technologies of academic publishing. The current moment is one of experimentation, with the opportunity and indeed imperative for new 
platforms and relationships to arise, likely to result in further innovations that will change the nature of both academic publishing and academic disciplines.

\section{Editor views on reviewing and reviewers}

As presaged in the previous paragraph, peer review is today the cornerstone of the entire academic system. Yet the work of reviewing submitted manuscripts is completely voluntary and nontransparent: an almost-invisible aspect of the contemporary academic workload. The journal editor makes the first judgement of whether or not a manuscript is suitable for the journal before it goes to the peer review process. All the Editors acknowledged the importance of reviewing and reviewers in shaping the contents of their journals and the field of scholarship. Some of the journals run a review board, while for others the editor finds reviewers for each individual manuscript. The Editors referred to a gap in practice: a lack of training about peer review. A second challenge is achieving genuinely blind peer review in a small field such as philosophy of education.

Reviewers are increasingly hard to find, given higher volumes of publishing, heavier academic workloads and the diversification of the field, and most of the Editors spoke of related problems, firstly in securing suitable reviewers, and secondly in obtaining timely, robust reviews. Some reviewers make unbalanced judgements about manuscripts written in their own fields, or those in which they have no real interest. In some cases, reviewers inappropriately use the review as a chance to demonstrate what they know. Reviews are subjective in the sense that they reflect someone's response to a manuscript, and some Editors spoke of instances where a manuscript clearly 'troubles' a particular reviewer. Editors will edit reviewer comments before sending them to authors, to neutralise and balance unconstructive or emotive comments.

Reviews are like 'mini-essays' and the Editors acknowledged the large amount of work done by reviewers. While reviewer expertise and diligence is crucial to the overall quality of the journal, however, editors are not obliged to follow the recommendations by reviewers about whether or not a particular manuscript should be published. Some of the Editors said serious discrepancy between reviewers was uncommon, while others said it happened frequently. Reviewing is 'not a vote' and the editor is more interested in the grounds for the decision than the publication decision itself, returned by each reviewer. The Editors pointed to the complicated set of working relationships by which mutual respect is maintained between reviewers, editors and authors.

The history of peer review dates back to its introduction by the Edinburgh Royal Society in 1731 as a form of insurance against libel, before evolving into the basis of the development of academic 
publishing, a history that is directly connected to the contemporary publishing world. Peer review occurs differently in different fields, but is generally a conservative force since it involves older scholars making judgements about the work of junior and emerging scholars. Hence peer review is also an ideological system through which power controls knowledge. Michael Peters suggests open peer review systems are a possible avenue by which academics may be able to regain control over their intellectual labour and the freedom to teach, publish, profess and learn. All the Editors expressed a view of the underlying purpose of reviewing as helping authors improve their manuscripts to publishable quality. Viewed thus, reviewing is a service done by academics to the author, the journal and the field.

\section{The ethics of editing}

Facilitating this form of service to authors, to the field and broader society has moral dimensions that our Editors explained lucidly. Fundamental to their work were two things: firstly, the capacities of judgement - that is, their ability to make a justifiable decision about the value of a submitted article; and secondly, their extensive professional social connections, which enabled them to make the right kinds of matches between the submitted work and its ideal reviewer. Some spoke of the ethical challenges of doing justice to those individual people - reviewers and authors - with whom they have established relationships within their academic networks. These relationships were often characterised by the concepts of care and respect that extended interpersonally but also contained a kind of reverence towards more abstract participants in the editorial project, such as future generations of scholars, and philosophers of the past. Furthermore, the ethics of editing were usually framed by epistemic concepts, reflecting that intellectual and moral values are intertwined in the field of philosophy of education.

Caring can take its toll when difficulties arise: Gert Biesta and Nicholas Burbules noted the difficulty of finding out things about reviewers that are unpalatable, such as unreliability or a tendency to insult authors, while Paul Smeyers remarked that a rejected paper receives just as much constructive criticism as one accepted under the revise-and-resubmit category. The larger, more abstract targets of a journal editor's sense of moral responsibility were commented on in these interviews with a sense of profound respect approaching awe. For example, the Editors value the integrity of the field of philosophy of education in terms of both its educational and philosophical dimensions, and its epistemic qualities - that is, what makes philosophical work different from other disciplines, such as the sciences. They express respect for the work of historically-significant philosophers, and a concern about the influences that prevent the flourishing of philosophical knowledge in contemporary societal conversations about education. They anticipate that perennial, often highly technical questions will 
continue to make contributions to the educational landscape and fascinate future scholars who are not yet here.

Our Editors spoke about the kinds of virtuous characteristics they believe are important to the performance of their roles, noting ways their personal characteristics and life histories interact with formal role expectations. At the top of this list is 'keen judgement' and a capacity for evaluating argument. Chris Higgins suggested the ethical identity of an editor is relational, in the sense that the editor and their community have mutual responsibilities to each other. Editors seek to cultivate in themselves and in their reviewers a kind of critical sympathy towards the author's proffered work, which allows for the most productive form of interpretation and collaborative development of the strength of the manuscript. Paul Smeyers argued it is imperative an editor has quality as their top priority, so therefore, it is crucial for an editor to manifest open-mindedness in a robust form. Michael Peters also advocated for open-mindedness as a virtue; one he argues is most valuable in its 'radical' form.

The Editors shared a few guidelines or heuristics they use to assist their decisions in satisfying complex ethical imperatives. These pieces of collective wisdom include: requesting authors to support the standing of the field by referring to the work of other educational philosophers; continuing to read and engage widely with current research in order to accurately recognise significant new work; avoiding the use of strict criteria by appreciating that substance and style are inseparable in the evaluation of philosophical work; and committing to the radical challenges of genuine collaboration. The Editors, above all, demonstrate dedication to a role that often places extremely high demands on them intellectually, ethically and personally, and one that they only cautiously recommended others take up, given the current turbulent state, and uncertain future of publishing, in the field of philosophy of education.

\section{The future of publishing and philosophy of education}

The current challenges facing philosophy of education arise within the context of larger changes in the university and the academy as a whole. Education is the most recent social science discipline to emerge, and the full acceptance of education into the university curriculum after 'a century-long struggle' is seen from a United Kingdom perspective as evidence of the postmodernisation of the university (Furlong, 2013, p. 4): 'in the end, the victory was a pyrrhic one given the extension of government control to the universities in the late twentieth century' (p. 5). An Editor is concerned to keep canons of academic quality intact whilst simultaneously reinventing practice for better representation in a diverse world. University work has come increasingly under the control of 
managerialism and accountancy practice. The resulting instrumentalisation of academic work; the rise of generic publishing metrics of little worth in our field; and what our Editors see as an antiintellectual bias in tertiary teacher education, have converged to put intense pressure on the future of publishing for written scholarship in philosophy of education. Some Editors were upbeat about the field's capability to take the helm for the academy as a whole, to 'rescu[e] the university project' (the subtitle of Furlong, 2013) and steer towards new and unbounded horizons, but others were more cautiously pessimistic, due to their recognition of concrete, systemic and local limitations.

The disappearance of philosophy of education from university calendars as a recognised subdiscipline of study, and the associated scarcity of research funding to support postgraduate work, combines with the ascendancy of 'fast knowledge, fast publishing' to support the concerns expressed by our Editors about the possibility of longer-term intergenerational loss of knowledge about publishing in philosophy of education. There is clearly a chain of consequences whereby loss of jobs in philosophy of education may endanger the future viability of journals in the field, associated with a decline of publishing opportunities, editorial knowledge, and ultimately levels of disciplinary knowledge.

In this climate it is profoundly important to re-conceptualise professional education for scholars in philosophy of education. Opportunities are needed for emerging scholars in Continental, Eastern, Western and Indigenous philosophical cultural traditions to engage in rich, educative conversations with established editors and leading scholars, in order to strategically facilitate and accelerate the processes of succession and adaptation, demanded by the rapid, ongoing transformation of the academic publishing landscape. Learned societies, conferencing, mentoring groups and digital technologies provide sites in which these conversations might take place, with some losses by comparison with older systems, as well as new affordances. Digital connectivity in particular has the potential to catalyse novel rapid-fire forms of intellectual mentoring, collaboration, writing projects, and life. Use of internet calls and conferences as means by which to complete the interviews in this issue is a case in point. Our Editors described their active roles in broadening representation on journal editorial boards for greater gender equality and cross-cultural fertilization, and providing for the induction of early career academics 'behind the publishing curtain' - projects they see as essential to the longevity and integrity of their journals, and the field as a whole.

Recognising that early career researchers are under pressure to publish, our Editors had several suggestions for developing the philosophical integrity of their work. The review process can be of significant benefit to early career researchers when considered constructive comments are provided 
by more established scholars: this benefit depends on the editor's capacity to make a good match between manuscript and reviewer. To enhance their gains from this process, early career researchers need to develop familiarity with the work published in the intended journal, and a sense of the landscape in which their research appears. Supervisors and co-authoring are other avenues for mentoring in publication, but the Editors recognised that nothing can replace thorough knowledge of the history of philosophical and educational ideas.

Mentoring and support for the next generation of educational philosophers, in response to the acknowledged pressure on academic succession and representation, is part of the role taken on by those who create and manage the field's published research record. Educational philosophy is very rich in books, articles, interviews and dedicated journals that can be studied by future generations. There is also a burgeoning stock of digital recordings, in which novices can hear scholars speak about their work. There are groups where novice scholars are given insight into the skills of reviewing, or opportunities to begin something completely new. It is clear that aspiring early career philosophers of education need to take full, active responsibility for finding mentors and opportunities, by participating in learned societies, collaborations and scholarly conversations, especially through conferencing, and beginning to think in expansive, perhaps novel and unconventional, ways about the field.

With this in mind, although the Editors clearly care deeply about the integrity of philosophy of education, they argued that educational philosophers should look beyond strict disciplinary borders. The Editors spoke about the need for philosophers of education to be open to other fields and scholars with different genealogies, in related humanities areas such as sociology, gender studies, cultural and media studies, and beyond. There is potential to reconsider the relationship between philosophy and psychology, and to build interdisciplinary collaborations based on educational concerns shared with disciplines such as engineering, medicine and the sciences. Philosophy of education would benefit from welcoming these disciplines, forging stronger links and projects that, among other things, test the boundaries between theoretical and empirical research. Ultimately, the aim is to develop broad and inclusive forms of philosophical literacy. Interdisciplinary collaborations allow scholars to develop and establish narratives about the relevance and value of educational philosophy to concrete educational problems, and contribute to tangible outcomes as demanded by the prevailing instrumentalist research rationale.

The perception of philosophy of education as a useful and productive enterprise is an area where our Editors recognised historical failings, driven by a tendency towards in-house conversations and 
technical, specialised work. Some Editors spoke about the clarity, rigour and critical insight that philosophical argumentation can offer to educational research, and related experiences of colleagues from other areas of educatonal research expressing appreciation when these kinds of skills are brought to the university committee table. Philosophy of education can make significant contributions to the debates in learning, policy, ethics, and populist trends in teaching practice. Mechanisms for 'selling' educational philosophy might be rejected as antithetical to the field, but are becoming vital due to the increasingly isolated conditions in which philosophers of education are working, within faculties and schools of education.

The demise of 'pure' philosophy of education positions is imminent. Future scholars of educational philosophers will neither look nor be the same as in the past, and their employment prospects will differ significantly. It is highly unlikely that, in the future, educational philosophers will be recognised as such, because even today, positions of philosophy of education within faculties and schools of education have nearly disappeared. Our Editors recognised that the specialised academic positions they currently hold are not being renewed, and that careful ongoing negotiations with their employers are needed to ensure their roles as journal editors continue to be supported. These factors work together to make it even more important that the future generations of educational philosophers: are capable of working across fields in interdisciplinary research; use the connectivity of social media to raise awareness of their work; and are able to communicate effectively about the special skills and attributes provided by philosophical training.

\section{Conclusion}

These interviews have surfaced a gap in disciplinary practice: providing learning opportunities in the role, skills and ethics of reviewing practice for academic journals. Reviewing is one major component of the embryonic curriculum for the emerging enterprise of editorial education. Induction and training programmes in reviewing may be fruitful to consider for journals and learned societies in philosophy of education.

The special characteristics our expert group display lend credibility to the idea that editing in philosophy of education is one of the most demanding roles in today's world of academic publishing. Editing in philosophy of education seems to have its own role-specific ethics that are inseparable from the discipline, and in which life histories, collaborative fertility, commitment and care, and extraordinary clarity of thought, merge in each editor's unique understanding of their work. 
There is clearly a need for the field of philosophy of education to pro-actively build and secure its own future. While fast disappearing as an autonomous entity in the institutional structure of today's university, the Editors' collective vision for the future of the discipline lies in the dissemination of philosophy of education theory and practice across the academy, through interdisciplinary collaborations, methodological pluralism and interculturalism. The six Editors in this issue constitute an expert group in the discipline, with whom the conversation of this project has been a rare privilege, an immense pleasure, and a rich source of learning of vital importance to us all.

\section{Reference}

Furlong, J. (2013). Education - an anatomy of the discipline: rescuing the university project? London and New York: Routledge. 